Anales de Literatura Hispanoamericana

ISSN-e: 1988-2351

\title{
50 años de Anales de Literatura Hispanoamericana
}

\author{
Evangelina Soltero Sánchez ${ }^{1}$
}

[en] 50 years of Anales de Literatura Hispanoamericana

Cómo citar: Soltero Sánchez, E. (2021) 50 años de Anales de Literatura Hispanoamericana, en Anales de Literatura Hispanoamericana 50, 13.

Hace 50 años, en 1972, Francisco Sánchez Castañer fundaba la revista Anales de Literatura Hispanoamericana, la primera publicación académica española centrada, exclusivamente, en estudios en torno a la producción literaria en lengua española del continente americano. Aquel primer número ofreció una serie de artículos que abarcaban desde investigaciones dedicadas a obras de la época virreinal, como "El novelista Gonzalo Fernández de Oviedo, alias de Sobrepeña"2 (autoría de Juan Bautista Avalle Arce), hasta reseñas de la literatura más contemporánea con las de Viernes de Dolores ${ }^{3}$, de Miguel Asturias, o de El zorro de arriba y el zorro de abajo ${ }^{4}$, de José María Arguedas.

Del estudio de las crónicas al análisis de las obras más recientes, las páginas de Anales durante estos cincuenta años han dado cuenta de la evolución de la literatura hispanoameircana, así como del devenir y evolución de los estudios hispanoamericanistas en los cinco continentes. Y no es esto exageración, como el lector curiso podrá comprobar.

Cinco décadas después, no hemos cambiado, al menos no en lo esencial. Exteriormente hemos evolucionado: las portadas se han estetizado, la estructura interna se ha ido matizando y hemos pasado del papel al mundo digital. Pero el objetivo siguen siendo el mismo, ofrecer un espacio de debate, análisis y reflexión en torno a la literatura hispanoamerica.

En este volumen de 2021 inauguramos una sección monográfica, "Escrituras virreinales", que viene a unirse a las dos ya existentes: "Monografía" (a propuesta de grupos de investigación en torno a un tema de estudio) y "Archivo Rubén Darío" (dedicada a estudios sobre la obra del autor nicaragüense, así como de la literatura finisecular). Se mantienen, por supuesto, la sección "Miscelánea" y la "Joven Crítica". En la sección "Reseñas" seguimos dando cabida a recenciones de estudios críticos sobre Literatura Hispanoamericana.

Solo nos queda decir que agradecemos a los colaboradores de la revista (los que escriben en ella, los que la leen, los que hacen ambas cosas) su fidelidad y el que nos hayan acompañado en este proyecto. Esperamos que nos sigan acompañando, ¿cuánto?...., todo lo que podamos.

Gracias de parte de todos los que conformamos Anales de Literatura Hispanoamericana.

\footnotetext{
${ }^{1}$ Universidad Complutense de Madrid. España

Email: esoltero@ucm.es

${ }^{2}$ Dedicado a la novela de cabellería firmada por Fernández de Oviedo, el Claribalte (ALH, vol. 1, 1972, págs. 143-154).

${ }^{3}$ Buenos Aires: Losada, 1972.

${ }^{4}$ Buenos Aires: Losad, 1971.

${ }^{5}$ Sería más correcto decir que "recuperamos". En los volúmenes 23, 24 y 25 "Letra coloniales" fue la sección monográfica dedicada a los estudios de literatura virreinal, siendo el coordinador de ésta Luis Íñigo Madrigal. Sin embargo, no tuvo continuidad. Esperamos ahora que la sección "Escrituras virreinales", coordinada por Esperanza López Parada y Paloma Jiménez del Campo sea de larga vida.
} 